\section{PSQ-138 INFLUENCE OF ANTIBIOTIC STEWARDSHIP PROGRAMME INTERVENTIONS IN A HOSPITAL AT HOME UNIT}

${ }^{1}$ A Lázaro Cebas*, 'P Tejedor Prado, 'E Izquierdo García, 'A Such Díaz, 'I Cañamares Orbis, 2) Garrido Dorronsoro, ${ }^{3} \mathrm{~L}$ Cano Alcalde, ${ }^{3} \mathrm{JL}$ Fraile González, ${ }^{4} \mathrm{E}$ Palencia Herrejon ${ }^{5}$ B Sánchez Artola, ${ }^{1}$ I Escobar Rodríguez. 'Hospital Universitario Infanta Leonor, Pharmacy, Madrid, Spain; ${ }^{2}$ Hospital Universitario Infanta Leonor, Emergency Medicine, Madrid, Spain; ${ }^{3}$ Hospital Universitario Infanta Leonor, Hospital at Home Unit, Madrid, Spain; ${ }^{4}$ Hospital Universitario Infanta Leonor, Intensive Care Medicine, Madrid, Spain; ${ }^{5}$ Hospital Universitario Infanta Leonor, Internal Medicine, Madrid, Spain

\subsection{6/ejhpharm-2021-eahpconf.257}

Background and importance Hospital at home $(\mathrm{HaH})$ units provide hospital level care at home to patients who would otherwise remain hospitalised. This hospitalisation model is growing as it saves costs, reducing hospital stay and complications such as nosocomial infections. Antibiotic stewardship programmes demonstrated success in conventional hospitalisation, and these interventions might be extended to $\mathrm{HaH}$ units. At the beginning of 2019, the antibiotic stewardship programme (ASP) made two interventions in the $\mathrm{HaH}$ unit: to prescribe fluoroquinolones only to patients with no safer alternatives based on the restriction made by the Spanish Agency of Medicines and Medical Devices (AEMPS) in 2018, and the advice to reduce the prescribed dose of cefixime from $400 \mathrm{mg} / 12$ hours to 400 $\mathrm{mg} / 24$ hours.

Aim and objectives The aim of the present study was to analyse the influence of the ASP interventions in a $\mathrm{HaH}$ unit.

Material and methods An observational, descriptive, cross-sectional study was carried out. Antibiotic consumption data from January 2017 to December 2019 were analysed. Defined daily dose (DDD) per 100 bed days was used as the indicator to measure antibiotic consumption, and increases or decreases in consumption were expressed in absolute terms. Data analysis was carried out using Microsoft Excel 2013.

Results Global antibiotic consumption was reduced progressively since 2018: 133.85 DDD/100 bed days (2017); 127.02 DDD/100 bed days (2018) and 101.95 DDD/100 bed days (2019). Fluoroquinolone consumption was 26.18 DDD/100 bed days in 2017. Since the recommendation made by the AEMPS, a more rationale use was observed in 2018 (21.62 $\mathrm{DDD} / 100$ bed days). After the ASP recommendations, its consumption fell to $15.16 \mathrm{DDD} / 100$ bed days in $2019(14.40 \%$ reduction 2018-2019). Cefixime consumption was 17.74 $\mathrm{DDD} / 100$ bed days in 2017 and increased to $20.62 \mathrm{DDD} / 100$ bed days in 2018. After the ASP intervention, it was reduced to $11.12 \mathrm{DDD} / 100$ bed days in 2019 (7.13\% reduction 20182019).

Conclusion and relevance Antibiotic stewardship programme interventions were effective in reducing antibiotic consumption in the $\mathrm{HaH}$ unit. Prescription restrictions related to fluoroquinolones due to their safety profile and cefixime dosing intervention were effective and reflected a reduction in consumption. HaH units could potentially benefit from the positive effects of antibiotic stewardship teams as conventional hospitalisation units.

\section{REFERENCES AND/OR ACKNOWLEDGEMENTS}

Conflict of interest No conflict of interest

\section{PSQ-139 PRESCRIPTIVE APPROPRIATENESS OF ANTIBIOTIC THERAPIES: CRUCIAL ROLE OF THE HOSPITAL PHARMACIST}

${ }^{1} \mathrm{P}$ Sorice*, 'S Corridoni, 'L Armillei, ${ }^{1} \mathrm{~F}$ Gasbarri, ${ }^{1} \mathrm{G}$ Di Florio, ${ }^{2} \mathrm{~S}$ Pizzica, ${ }^{2} \mathrm{C}$ Cinalli, ${ }^{1} \mathrm{G}$ Di Carlo, ${ }^{1}$ A Romagnoli, 'L Auriemma, ${ }^{1} \mathrm{~A}$ Costantini. ${ }^{1}$ Hospital Santo Spirito, Pharmacy, Pescara, Italy; ${ }^{2}$ Swisslog Staff, Pharmacy, Pescara, Italy

\subsection{6/ejhpharm-2021-eahpconf.258}

Background and importance In the context of the single dose, the pharmacist is involved in the validation of patients ${ }^{6}$ personalised therapies, attempting to minimise errors in therapy.

Aim and objectives The aim of this study was to evaluate, through the computerised prescription, the increase in prescribing appropriateness of antibiotic therapy, following notification by the pharmacist, with relative money saving costs.

Material and methods The analysis was carried out by extrapolating, from the unit dose (UD) software, prescriptions of antibiotics subjected to a single request motivated (SRM) in the period from 1 January 2019 to 31 December 2019. We analysed inappropriate prescriptions where the hospital pharmacist affixed the 'note', sent immediately to the prescriber. These prescriptions were divided into inappropriate for: posology, duration of therapy and interaction/incompatibility. Subsequently, the variation in prescriptions due to the pharmacist's intervention was evaluated (ie, the number of inappropriate prescriptions which were changed by the physician was extrapolated). In the pharmacoeconomic field, we evaluated the expenditure of inappropriate prescriptions without notification of the hospital pharmacist and the savings obtained following the change in therapy.

Results During the study period, total prescriptions of antibiotics with SRM were 2067; 216 (10.45\%) were not appropriate. The number of prescriptions modified following the pharmacist's intervention was 104 (48\%). Pharmacoeconomic analysis showed that the expenditure incurred for the dispensation of antibiotics related to inappropriate prescriptions changed by notification from the pharmacist was $77537 €$ for 12 months. If the physician had not modified the therapies, the expenses would have been $162762 €$ and therefore the amount of money saved was $85225 €$ in 12 months. Conclusion and relevance The control and validation of medical prescriptions by the pharmacist produced an important added value to the risk management process, in that in almost $50 \%$ of cases the pharmacist's notes led to an actual change in the medical prescription. The use of computerised prescriptions and single dose management contributed strongly to the objectives of verifying prescriptive appropriateness as a tool to govern effectiveness, efficiency and costs in healthcare.

\section{REFERENCES AND/OR ACKNOWLEDGEMENTS}

Conflict of interest No conflict of interest

\section{PSQ-140 UNIT DOSE SYSTEM: MODEL OF IMPLEMENTATION OF THE ANTIMICROBIAL STEWARDSHIP}

${ }^{1} \mathrm{P}$ Sorice*, ${ }^{*} \mathrm{~S}$ Corridoni, ${ }^{1} \mathrm{~L}$ Armillei, ${ }^{1} \mathrm{~F}$ Gasbarri, ${ }^{1} \mathrm{G}$ Di Florio, ${ }^{2} \mathrm{~S}$ Pizzica, ${ }^{2} \mathrm{C}$ Cinalli, ${ }^{1} \mathrm{G}$ Di Carlo, 'A Romagnoli, 'L Auriemma, 'A Costantini. 'Hospital 'Santo Spirito' Pescara, Pharmacy, Pescara, Italy; ${ }^{2}$ Swisslog Staff, Pharmacy, Pescara, Italy

10.1136/ejhpharm-2021-eahpconf.259 